Portland State University

PDXScholar

\title{
To Branch Out or Stay Focused?: Affective Shifts Differentially Predict Organizational Citizenship Behavior and Task Performance
}

\author{
Liu-Qin Yang \\ Portland State University \\ Lauren S. Simon \\ Portland State University \\ Lei Wang \\ Tsinghua University \\ Xiaoming Zheng \\ Tsinghua University
}

Follow this and additional works at: https://pdxscholar.library.pdx.edu/psy_fac

Part of the Industrial and Organizational Psychology Commons

\section{Let us know how access to this document benefits you.}

\section{Citation Details}

Yang, L.-Q., Simon, L., Wang, L., \& Zheng, X. (Accepted). To branch out or stay focused?: Daily affective shifts differentially predict organizational citizenship behavior and task performance. Journal of Applied Psychology.

This Post-Print is brought to you for free and open access. It has been accepted for inclusion in Psychology Faculty Publications and Presentations by an authorized administrator of PDXScholar. Please contact us if we can make this document more accessible: pdxscholar@pdx.edu. 
To Branch Out or Stay Focused?: Affective Shifts Differentially Predict Organizational

Citizenship Behavior and Task Performance

\author{
Liu-Qin Yang \\ Department of Psychology \\ Portland State University \\ 1725 SW Broadway St \\ Portland, OR, 97201 \\ Email: lyang@pdx.edu \\ Lauren S. Simon \\ School of Business Administration \\ Portland State University \\ 631 SW Harrison St \\ Portland, OR, 97201 \\ Email: lausimon@pdx.edu \\ Lei Wang \\ Room 344, Weilun Building \\ Leadership and Organization Management Department \\ School of Economics and Management \\ Tsinghua University \\ Beijing 100084, China \\ Email: wanglei@sem.tsinghua.edu.cn \\ Xiaoming Zheng \\ Room 436, Weilun Building \\ Leadership and Organization Management Department \\ School of Economics and Management \\ Tsinghua University \\ Beijing 100084, China \\ Email: zhengxm@sem.tsinghua.edu.cn
}

Please cite this article as

Yang, L.-Q., Simon, L., Wang, L., \& Zheng, X. (Accepted). To branch out or stay focused?: Daily affective shifts differentially predict organizational citizenship behavior and task performance. Journal of Applied Psychology. 
Authors' note: The first two authors contributed equally to this article; their order of authorship was determined randomly. We thank Action Editor Lillian Eby and two anonymous reviewers for their constructive guidance during the review process. We also thank Shung Jae Shin for his helpful feedback on a previous version of this manuscript. This research was supported by the National Natural Science Foundation of China Grants \#71272022, awarded to Xiaoming Zheng. Correspondence concerning this article should be addressed to Lei Wang or Xiaoming Zheng, Weilun Building, Leadership and Organizational Management Department, School of Economics and Management, Tsinghua University, Beijing, 100084, China. Email: wanglei@sem.tsinghua.edu.cn or zhengxm@sem.tsinghua.edu.cn 


\begin{abstract}
We draw from personality systems interaction theory (PSI; Kuhl, 2000) and regulatory focus theory (Higgins, 1997) to examine how dynamic positive and negative affective processes interact to predict both task and contextual performance. Using a twice-daily diary design over the course of a three-week period, results from multi-level regression analysis revealed that distinct patterns of change in positive and negative affect optimally predicted contextual and task performance among a sample of 71 individuals employed at a medium-sized technology company. Specifically, within persons, increases (upshifts) in positive affect over the course of a work day better predicted the subsequent day's organizational citizenship behavior (OCB) when such increases were coupled with decreases (downshifts) in negative affect. The optimal pattern of change in positive and negative affect differed, however, in predicting task performance. That is, upshifts in positive affect over the course of the work day better predicted the subsequent day's task performance when such upshifts were accompanied by upshifts in negative affect. The contribution of our findings to PSI theory and the broader affective and motivation regulation literatures, along with practical implications, are discussed.
\end{abstract}

Key Words: Positive Affect, Negative Affect, Affective Shift, Organizational Citizenship Behavior, Task Performance 
Over the past decade, research has increasingly recognized the important role of affect in the workplace (Barsade \& Gibson, 2007, 2012; Brief \& Weiss, 2002). As noted by Barsade and Gibson (2012), affective experiences permeate the workplace, and the "affective revolution" has generated a large body of research on the relations between affect and employee and organizational outcomes (Barsade, Brief, \& Spataro, 2003). Employees' affective experiences have, for example, been consistently linked to employee work motivation (e.g., Bledow, Schmitt, Frese, \& Kühnel, 2011), task performance (e.g., Johnson, Tolentino, Rodopman, \& Cho, 2010; Shockley, Ispas, Rossi, \& Levine, 2012), OCB (e.g., George, 1991), counterproductive work behavior (e.g., Johnson et al., 2010), and creativity (e.g., Baas, De Dreu, \& Nijstad, 2008).

Affect can be defined as "a phase of neurobiological activity that is experienced as motivational and informational and that influences thought and action, a felt cognition or action tendency" (Izard, 2009, p. 3). Positive and negative affect are recognized as relatively independent processes, although both have been conceptualized and measured as traits - general tendencies to experience certain feelings, and as states - more short-lived emotional experiences that become activated in response to environmental stimuli (Izard, 2009; Watson, 1988).

The literature on affective traits and states in the workplace has made considerable progress in recent years, yet challenges remain with respect to our understanding of how affect influences employees' behaviors. First, theoretical development of research on affect has been somewhat stifled by the widely held view in psychology that positive and negative affect possess separate nomological networks, with positive affect linked mainly to positive work outcomes, and negative affect linked mainly to negative work outcomes (Lyubomirsky, King, \& Diener, 2005; Thoresen, Kaplan, Barsky, Warren, \& de Chermont, 2003). Accordingly, many of the 
existing models of affect do not sufficiently discuss the interplay of positive and negative affect in the processes leading to employee behavior (e.g., Weiss \& Cropanzano, 1996).

Additionally, prior within-individual research on affect in organizations has primarily focused on explaining the influence of affect levels at a given point in time on outcomes, rather than on developing theoretically-grounded propositions on within-individual shifts in affect during a given time period (e.g., Dalal, Lam, Weiss, Welch, \& Hilin, 2009). Yet, the distinction between studying levels of affect and shifts in affect at the within-individual level is an important and theoretically meaningful one. When focusing on within-person levels of affect, the research question addresses whether a person who experiences a particular level of momentary affect is also likely to experience or engage in a specified outcome during that or a subsequent measurement period. But a temporal focus in which shifts in affect from one time point to the next are taken into account is likely to provide another useful perspective, because the consequences of an affective experience at any given time are likely to depend to an extent on one's preceding experience of affect (Bledow et al., 2011). This point of view is consistent with PSI theory (Kuhl, 2000) — a self-regulatory theory of affect and motivation used to ground our hypotheses - which suggests that it is the effective upregulation and downregulation of positive and negative affect in appropriate situations that is most likely to lead to adaptive outcomes, with persistence of any particular affective state over time potentially leading to maladaptive outcomes (Kuhl \& Koole, 2008; Gruber, Mauss, \& Tamir, 2011).

Of course, beyond studying shifts in positive or negative affect alone, it is even more informative to study them together, because simultaneous fluctuations in both positive and negative affect should best reflect affective dynamics in daily work settings, and thus should play a key role in regulating employees' motivation and behavior. For example, an unexpected 
challenging task assignment may result in a change from a quiescent and calm state (low in positive and negative affect), to an excited and anxious state (high in positive and negative affect), which can motivate higher performance. Yet, the dynamic processes via which the interplay of positive and negative affective experiences drive downstream employee behavior are not yet well understood. Only two published empirical studies (Bledow et al., 2011; Bledow, Rosing, \& Frese, 2013) have examined shifts in positive and negative affect in tandem, and both studies focus on a single pattern of interaction in positive and negative mood change. More specifically, Bledow et al. (2011) focuses on how periods of high negative affect followed by high positive affect influence the outcome of employee engagement, whereas Bledow et al. (2013) focuses on how upshifts in positive affect coupled with downshifts in negative affect influence employee creativity.

In the present study, we extend the research of Bledow and colleagues by studying cooccurring positive and negative affective shift in relation to two additional outcomes - task performance and $\mathrm{OCB}$ — which are among the most important indicators of job performance (Motowidlo \& Kell, 2013). As a primary contribution, we draw from Kuhl's (2000) PSI theory and regulatory focus theory (Higgins, 1997) to examine an additional pattern of affective shift (co-occurring upshifts in positive and negative affect) in relation to task performance. In doing so, we extend PSI theory by helping to further our understanding of the exact role that patterns of shift in affective tone over particular time intervals plays in influencing work outcomes.

Our research also contributes to the literature on OCB and task performance. Although within-person relationships between positive affect and OCB and task performance have tended to be positive (e.g., Dalal, et al., 2009; Yeo, Frederiks, Kiewitz, \& Neal, 2014), prior research has shown considerable variability in within-person effect sizes linking positive affect to these 
outcomes (Lyubomirsky et al., 2005; Shockley et al., 2012). Thus, the conditions under which positive affect is most likely to benefit OCB and task performance remain unclear. In simultaneously studying the effects of different patterns of shift in positive and negative affect on these outcomes, our research offers a more fine-grained and complete picture of the powerful ways in which affect can influence these important work behaviors ${ }^{1}$. Such knowledge is essential for effectively motivating these behaviors in the workplace, as well as for further developing an emotion and motivation regulation theory that is capable of predicting dynamic and differentiated goal-directed work behavior.

It is also worth noting that prior field studies examining affective shift in relation to workplace motivation and behavior have focused on examining how shift in affect over the course of the workday influences outcomes measured concurrently with affect (Bledow et al., 2011, 2013). In testing our hypotheses, we examine task performance and OCB as a result of shift in the previous day's affect. There are both methodological and substantive advantages to this approach. First, such a design, in which measurement of the predictors and criteria are separated in time, allows us to establish temporal precedence. Temporal precedence provides stronger support for hypothesized causal relationships in correlational research (Brewer, 2000). Conversely, in study designs that employ concurrent measures of affect and outcomes, it is more difficult to establish whether shifts in affect are a result of the hypothesized outcome or whether the hypothesized outcomes were, in fact, a result of the shifts in affect.

From a more substantive perspective, as researchers using daily, lagged designs have noted (e.g., Judge, Simon, Hurst, \& Kelly, 2014), and as self-regulatory (Kuhl, 2000) and appraisal theories of cognition and emotion would suggest (e.g., Lazarus, 1991), interpretive processes - consisting of a wide variety of conscious and subconscious cognitive, perceptual, 
and affective mechanisms individuals use to assign meaning to experiences - are responsible for linking daily experiences to reactions. Examples of these processes are cognitive appraisal, memory consolidation, and integration of information with existing schemata. A good deal of this interpretive processing is likely to occur during the hours after work (Judge et al., 2014). For instance, a large degree of memory and emotional processing occurs while sleeping, during which time our most salient affective memories are retained and important information from these memories is consolidated (van der Helm \& Walker, 2009). Neurobiological research also suggests that sleep recalibrates the brain's response to initial emotional events, allowing adaptive and accurate next day emotional processing of salient (threatening and rewarding) stimuli (Goldstein \& Walker, 2014). In sum, this evidence suggests that the time between workdays is a critical period during which daily affective experiences are interpreted, and such interpretations, in turn, influence the next day's behavioral responses.

In the sections to follow, we establish our theoretical model and hypotheses. We draw primarily from PSI theory (Kuhl, 2000), as its emphasis on intra-individual affective change makes it particularly useful for understanding the interplay between shift in positive and negative affect. In addition, we invoke tenets of regulatory focus theory (Higgins, 1997) to provide further rationale for the linkages between shift in affect and performance outcomes. Given our research focus on affective shift, we predominantly rely on empirical evidence from studies that examine affect in a more dynamic fashion, such as experience sampling methodology studies or studies that induce affect in a laboratory setting, to support our arguments.

\section{Theory and Hypotheses}

\section{PSI Theory and Affective Shift}


What sets PSI theory (Kuhl, 2000) apart from other self-regulatory theories is its explicit emphasis on the dynamic nature of affect regulation and the close associations between affect, cognition, motivation and personality systems. Another key difference between PSI theory and prior motivational theories is PSI theory's focus on function-based (e.g., intention memory functions to regulate or maintain goal intentions) rather than content-based motivational mechanisms (e.g., self-efficacy; Bandura, 1991). PSI theory presents four inter-related cognitive and motivational subsystems - intention memory, extension memory, intuitive behavior control, and object recognition - that each represent a "motivational" function regulated by positive and negative affective processes. Intention memory (IM) represents a slow, thorough, analytical thinking subsystem in charge of planning, whereas extension memory (EM) is a holistic subsystem that allows parallel processing and integration of environmental factors with personal values and experiences. Intuitive behavior control (IBC) represents an automatic motor control subsystem in charge of fast action implementation that is based on intuitive information processing, while object recognition (OR) governs analyses of new, unexpected experiences and modality-focused sensory processing.

These four subsystems constrain each other, and their interactions are further constrained or facilitated by affective changes, ultimately leading to balanced regulation of motivation and behavior. For instance, the IM subsystem tends to inhibit the IBC subsystem, and the interaction of these subsystems is influenced by positive affect. That is, inhibition of the IBC subsystem by the IM subsystem is weakened or released by upshifted positive affect, leading to a more active IBC subsystem. A more active IBC subsystem, in turn, results in faster implementation of actions and goals based on intuitive judgment, as well as engagement in exploratory thought and behavior at times (Fredrickson, 2005; Kuhl \& Kazén, 1999). Down-shifted positive affect, on the 
other hand, strengthens inhibition of the IBC subsystem by the IM subsystem, leading to a more active IM subsystem. A more active IM subsystem results in behaviors like plan making and delayed goal implementation, as individuals thoroughly analyze possible courses of action while maintaining goal intentions (Carver \& White, 1994; Kazén \& Kuhl, 2005).

Similarly, when the EM subsystem is strongly activated, the OR subsystem tends to be inhibited, and the interaction of these subsystems is regulated by negative affect. Inhibition of the OR subsystem by the EM subsystem is released by upshifted negative affect, leading to a more active OR subsystem as indicated by behaviors like becoming alert and open to unexpected or undesirable experiences, and focusing attention on specific aspects of a situation. Inhibition of the OR subsystem by the EM subsystem is strengthened by downshifted negative affect, leading to a more active EM subsystem; the more active EM subsystem then facilitates individuals to think more broadly (i.e., to use parallel processing — attending to both current and past personal experiences and contextual information such as work group dynamics), and enables them to integrate new experiences into existing networks of knowledge, experiences, and values (Baumann \& Kuhl, 2002). In short, PSI theory posits that affective regulation is key to understanding how motivational regulation (realized through the interactions of the aforementioned four subsystems) results in optimal or suboptimal behavioral regulation.

Our study applies and extends PSI theory's main tenets on affective regulation to explain how simultaneous intra-individual upshifts or downshifts in positive and negative affect predict work behavior. Accordingly, we establish four possible combinations of affective shift and use Figure 1 (quadrants A-D) to illustrate their differential implications for motivation and behavior; we relate these combinations to PSI theory's specific tenets wherever appropriate. With an upshift in positive affect and a downshift in negative affect (corresponding to more active IBC 
and EM subsystems; see Figure 1 quadrant A), individuals enter a motivational mode of selfregulation (e.g., a state of adaptiveness and self-motivation) where they tend to think broadly by taking into account personal and contextual information, make integrative judgments, and take fast action to implement goals (Kuhl, 2000). With upshifts in both positive and negative affect (corresponding to more active IBC and OR subsystems; see Figure 1 quadrant B), individuals tend to stay alert to threats (e.g., deadlines), yet focused on analyzing specific aspects of the situation, ultimately being able to generate and enact solutions to problems in a fast manner. With a downshift in positive affect and an upshift in negative affect (corresponding to more active IM and OR subsystems; see Figure 1 quadrant C) individuals enter a motivational mode of hesitation and preoccupation, where they stay alert to threatening problems or challenging goals, thoroughly analyze them, and maintain the intention to solve or accomplish them, but may be slow to take action due to inadequate concentration and distraction (e.g., conflicting goals and problems; Kuhl, 2000). Finally, with downshifts in both positive and negative affect (corresponding to more active IM and EM subsystems; Figure 1 quadrant D), individuals can think broadly by considering their personal perspectives (e.g., past (un)successful experiences) and the broader context (e.g., coworkers' needs) while analyzing multiple goals or ideas. Based on integration of pertinent information and analyses, they may then devise potential goal implementation plans in a slow and sequential manner. The present study focuses on understanding how the first two patterns of affective shift predict employee OCB and task performance (quadrants $\mathrm{A}$ and $\mathrm{B})$.

\section{Affective Shift and OCB}

We reason that an upshift in positive affect coupled with a downshift in negative affect (see Figure 1 quadrant A) is most likely to elicit OCB - discretionary behavior "that supports 
the social and psychological environment in which task performance takes place" (Organ, 1997, p. 95). Specifically, employees experiencing upshifted positive affect tend to be fast in initiating "broaden-and-build" thinking and behavior, including OCB such as helping coworkers and volunteering to work over-time (Dalal et al., 2009; Fredrickson, 2005; Kuhl \& Kazén, 1999). Upshifts in positive affect should also increase OCB by heightening the reward expectations associated with such behavior. According to regulatory focus theory (Higgins, 1997), promotion focus, which consists of both trait and state components, is associated with positive affect and eagerness to attain positive outcomes (e.g., rewards) through pursuing goals and aspirations. Indeed, evidence indicates that employees experiencing increased positive affect tend to report more attraction toward others and higher reward expectations for helping behavior; they also demonstrate more approach-oriented behavior focused on gains, which can include OCB (e.g., Clark \& Waddell, 1983).

Although upshifted positive affect should increase OCB, a simultaneously experienced downshift in negative affect should enhance this salutary effect. Specifically, downshifted negative affect can prompt employees to think broadly by considering both contextual and personal information (e.g., coworkers' needs, one's past experiences and strategies for helping coworkers [Bolte, Goschke, \& Kuhl, 2003; Förster \& Higgins, 2005]), and can help them to further integrate such information while devising action plans to work within the constraints inherent to fulfilling multiple work roles. Downshifted negative affect has also been linked to processes corresponding to reduced prevention focus — an orientation toward preventing losses and fulfilling obligations through vigilant and responsible behavior (Higgins, 1997) — including reduced avoidance motivation and lessened sensitivity to potential resource losses (e.g., Eddington, Majestic, \& Silvia, 2012), such as the time-related costs of performing OCB (Bolino, 
Klotz, Turnley, \& Harvey, 2013). These aspects of downshifted negative affect, when coupled with upshifted positive affect, should not only best facilitate fast integration of one's contextual and personal information and current demands, resulting in creative strategies to meet the needs of oneself and one's coworkers or workgroup (e.g., OCB), but should also provide a highreward, low-risk incentive for performing OCB. Although upshifts in positive affect should make salient the rewards of OCB, without a downshift in negative affect, the costs of OCB could also remain palpable.

Hypothesis 1: Change in negative affect over the course of a work day moderates the relationship between change in positive affect over the course of a work day and OCB the subsequent day, such that an upshift in positive affect is more positively related to $O C B$ when there is a corresponding downshift in negative affect.

\section{Affective Shift and Task Performance}

As we have argued previously, PSI theory suggests that upshifts in positive affect facilitate intuitive and integrative information processing which can help generate solutions to problems and enable fast action via mechanisms such as activation of the IBC subsystem (Kuhl, 2000). Moreover, research has shown that increased positive affect is associated with increases in expectancy motivation, goal setting motivation, and goal commitment (Fishbach, Eyal, \& Finkelstein, 2010; Ilies \& Judge, 2005), which, in turn, should increase the effort directed toward a particular goal (Locke \& Latham, 2006; Vroom, 1964).

It has, however, also been argued that upshifts in positive affect can signal that a specific goal has been partially attained, resulting in complacency and decreased effort (Carver \& Scheier, 1990). Negative affect may be a key determinant in whether upshifts in positive affect increase task performance. According to PSI theory, an upshift in negative affect should heighten activation of the OR subsystem, thereby focusing one's attention and enhancing alertness to any potential threats (Baumann \& Kuhl, 2002; Kuhl, 2000; Shackman et al., 2011), such as 
impending deadlines, or a lack of goal progress. Whereas upshifts in positive affect without upshifts in negative affect may breed complacency or exploratory behavior that can detract from task performance, and upshifts in negative affect unaccompanied by the uplifting motivational effects of upshifts in positive affect can hinder goal desirability and commitment leading to disengagement (Carver \& Scheier, 1990; Fishbach et al., 2010; Rothbard \& Wilk, 2011), upshifts in both positive and negative affect (see Figure 1 quadrant B) should provide "the best of both worlds" with respect to task performance. That is, upshifts in positive affect have motivating, solution-generating, and mobilizing functions that should enhance commitment to tackling immediate challenges and demands made salient by the alertness-enhancing and attentionfocusing functions associated with upshifts in negative affect.

Also consistent with these arguments is research on regulatory focus. As noted by Lanaj, Chang, and Johnson (2012), "Perhaps the optimal situation is one where the motivation to pursue a desired end-state (which coincides with a strong promotion focus) is paired with the motivation to avoid errors (which coincides with a strong prevention focus), thereby creating complementary push and pull forces that facilitate task performance" (p. 21; italics added for emphasis). Empirical evidence has indeed shown both strong promotion focus and prevention focus to be positively associated with daily evaluations of goal progress (Eddington et al., 2012).

Hypothesis 2: Change in negative affect over the course of a work day moderates the relationship between change in positive affect over the course of a work day and task performance the subsequent day, such that an upshift in positive affect is more positively related to task performance when there is a corresponding upshift in negative affect.

\section{Method}

\section{Participants and Procedure}

As part of a larger research project ${ }^{2}$, we recruited for this study a sample of full-time employees in a medium-sized technology company located in Northern China, which provides 
geographic information software and services. First, the research team sent a letter to 181 eligible employees, introducing the research project and its procedure. Afterwards, the research team had an onsite meeting with all interested employees, where confidentiality of survey responses was reiterated and potential benefits of the project (e.g., an organization-level technical report) were discussed. Consequently, 72 employees, who collectively represented all 12 departments in the organization, volunteered to participate in this study.

In the three weeks following the meeting, participants were asked to complete the scheduled web-based survey twice a day: once in the morning before they started working (approximately 9 a.m.) and once at the end of the work day before they left the office (approximately 5 p.m.). Two trained research assistants sent out text reminders to all participants' cell phones approximately 30 minutes before each scheduled survey. To accommodate participants who might arrive at or leave work earlier or later than the typical work schedule, we allowed the survey link to remain active for two hours (i.e., 8-10 a.m. and 4-6 p.m., respectively). The same research assistants contacted those participants who missed 3 surveys in a row, in order to document any unexpected changes that occurred and to facilitate future participation. During the three-week period, only one participant withdrew because of an unexpected schedule conflict. In total, 71 employees, representing $39 \%$ of all eligible employees, participated in this study. The average daily completion rate was $89.9 \%$ for morning surveys and $87.4 \%$ for afternoon surveys. On average, participants completed both the morning and afternoon survey on 12.08 days, leading to 858 sets of matched morning and evening observations. To test our hypotheses, we used 792 sets of matched prior-day morning and evening observations and their accompanying following-day evening observations. 
Among the 71 participants, $49 \%$ were female, and the average age was 27.77 years $(S D=$ 3.18). Their average organizational tenure was 2.40 years $(S D=1.89)$. Representing all departments in the company, participants held a broad range of jobs, such as electronic engineers, photographers, web administrators, accounting managers, and salespeople. Among them, approximately $1 \%$ were mid-level managers, $20 \%$ were first-line supervisors, and $79 \%$ were general employees. Approximately 4\% had a high school diploma, 24\% had an associate's degree, 54\% had a bachelor's degree, and $18 \%$ had a graduate degree.

\section{Measures}

All survey items and instructions were written and administered in the Chinese language. We adopted a translation-back translation approach (Brislin, 1980) by involving two researchers fluent in both Chinese and English. During the morning survey, participants reported state positive and negative affect; during the afternoon survey, participants reported state affect as well as their OCB and task performance. In a baseline survey that occurred approximately two weeks before the diary study, we included demographic variables and the control variables.

State positive and negative affect. Consistent with our conceptualization of affect, we measured morning positive and negative affect with the 20 -item positive and negative affect schedule (PANAS) scale (Watson, Clark, \& Tellegen, 1988), with 10 items for each dimension. In the afternoon, we measured positive and negative affect with the short-form of the PANAS (Thompson, 2007) which included 10 out of the 20 items from the PANAS ${ }^{3}$. We employed a shorter survey of affect in the afternoon in order to increase the participation rate and quality of responses by reducing the survey fatigue participants might experience at the end of a work day. The positive affect items that appeared in both the morning and afternoon scales were "alert," "inspired," "determined," "attentive," and "active"; the negative affect items that appeared in 
both scales were "ashamed," "nervous," "afraid," "upset," and "hostile”. Participants were instructed to report how they felt at that moment on a five-point Likert scale ranging from 1 (not at all) to 5 (extremely). For morning affect, the Cronbach's alpha averaged across 15 work days was .93 for positive affect and .87 for negative affect. For afternoon affect, average alpha was .80 for positive affect, and .81 for negative affect.

OCB. OCB was measured with an eight-item scale tailored and validated for diary studies (Dalal et al., 2009). Example items were, “Today I went out of my way to be a good employee," and "Today I tried to be considerate to others." Participants reported whether or not they had performed a specific behavior by answering 1 (Yes) or $0(\mathrm{No})$. Cronbach's alpha for this eight-item scale averaged across the 15 days was .74 .

Task performance. Task performance was measured with a single item, “Today I performed my job well," using a five-point Likert scale ranging from 1 (Not at All) to 5 (Strongly Agree). This item was used by previous researchers (Bakker \& Xanthopoulou, 2009; Goodman \& Svyantek, 1999).

Control variables. Although our primary focus was on the day level (Level 1) relationships between affective shift and employees' OCB and task performance, we did control for gender, organizational tenure, and trait positive and negative affectivity at the person level (Level 2). We did so because these variables have been shown to influence employee task and contextual performance and/or affect regulation (Bledow et al., 2011; McRae, Ochsner, Mauss, Gabrieli, \& Gross, 2008; Ng \& Feldman, 2010). Trait affectivity, including positive affectivity and negative affectivity, was measured using the 20-item PANAS scale (Watson et al., 1988). Participants were instructed to rate on a five-point scale the extent to which they had experienced each affect state in general, ranging from 1 (Not at All) to 5 (Very Much). The alpha reliabilities 
were .90 for positive affectivity and .88 for negative affectivity. Gender was coded as 0 (Male) and 1 (Female). Finally, we also controlled for the number of days on which participants missed one to two surveys during the course of the study at the person level, as well as day of the week at the day level, since it too has been shown to influence affect fluctuations (Egloff, Tausch, Kohlmann, \& Krohne, 1995).

\section{Analytical Strategies}

Because our data consisted of repeated measures nested within individuals, we estimated multilevel models using Mplus, version 7.11 (Muthén \& Muthén, 1998-2013) to test our hypotheses. Consistent with the proposed ordering of the variables, we forward lagged the dependent variables by one day, so that the dependent variables occurred the day after the affective shift. We also centered the predictor variables around each individual's mean in all of our analyses, so that Level 1 estimates represent strictly within-person effects, with coefficients denoting effects of the deviation of the $j^{\text {th }}$ person's score for a particular variable on day $i$ from the person's mean on that variable over the course of the study (Algina \& Swaminathan, 2011). The Level 2 variables were left uncentered. Further, to account for the fact that different forms of affective regulation may simultaneously influence contextual and task performance, we ran the Mplus models by simultaneously including both outcome variables.

In each of our models involving the effects of affect, we assessed shifts in positive and negative affect (main effects) using residual change scores rather than differences in raw scores. Residual change can be captured by entering afternoon (t2) levels of affect into the models while simultaneously controlling for morning (t1) levels of affect. As noted by Beldow et al. (2013), controlling for morning affect values allows afternoon affect values to be interpreted as deviations of actual afternoon affect values from those values that would be anticipated given the 
morning affect values (Rogosa, Brandt, \& Zimowski, 1982). Assessing change in this manner is preferable to measuring raw score change (Bledow et al., 2013; Campbell \& Kenny, 1999).

Consistent with previous research in this area, we also used the residual change approach to assess the interactive effects of change in positive and negative affect, which are of primary interest in this study. In doing so, we employed Bledow et al.'s (2013) methodology to calculate the interaction term. More specifically, we calculated a product term derived from separately computed residual values for positive and negative affect. These residual values were obtained by first separately regressing afternoon (t2) positive affect on morning (t1) positive affect and afternoon (t2) negative affect on morning (t1) negative affect. The resulting residual values were subsequently saved as variables and used to create the interaction term.

\section{Results}

Table 1 presents descriptive statistics and inter-correlations between theoretically relevant control variables and focal variables (affect, OCB, and task performance) at the day (above the diagonal) and person (below the diagonal) levels. Forty-nine percent of the variance in OCB was within-individual, and $59 \%$ of the variance in task performance was withinindividual. As shown in Table 1, at the day level, positive and negative affect in the morning were positively and moderately related to positive and negative affect in the afternoon, respectively (day-level $r=.23$ vs. .32, respectively, $p<.01$ ). At the person level, aggregated positive and negative affect in the morning were positively and strongly related to aggregated positive and negative affect in the afternoon (person-level $r=.96$ vs. .91, respectively, $p<.01$ ). Furthermore, the correlation between OCB and task performance was -.02 (n.s.) vs. .30 ( $p<.01)$, respectively for the day and person levels. Finally, two of the theoretically relevant control variables (positive affectivity and tenure) were related to at least one of the dependent variables. 
For example, organizational tenure was negatively related to task performance at the person level $(r=-.24, p<.05)$, perhaps, because experienced employees tend more toward task mastery than toward fitting in, and are more receptive to negative feedback (Fishbach et al., 2010), raising managers' and employees' own performance standards and expectations.

\section{Test of Hypotheses}

Table 2 presents results from two models that tested Hypotheses 1 and 2 simultaneously. Specifically, in Model 1, the coefficients for $\mathrm{t} 2$ (afternoon) positive and negative affect represent the relationships between positive and negative affect residual change over the course of the workday and subsequent-day OCB and task performance, respectively, as t1 (morning) positive and negative affect were essentially held constant. Furthermore, we used the residual change interaction term in Model 2 to test our corresponding hypotheses.

Hypothesis 1 focused on the relationship between changes in positive and negative affect from morning to afternoon and subsequent-day OCB. As shown in Table 2 (Model 1), change in negative affect over the prior day was positively related to OCB reported the following day ( $B$ $=.07, p<.01)$, while change in positive affect was not significantly related to OCB reported the following day $(B=.03$, n.s. $)$. Furthermore, Model 2 reveals that the interaction term of the residual scores of positive and negative affect significantly predicted OCB reported the following day $\left(B=-.15, p<.05, \Delta R^{2}=.02\right)$. That is, conceptually, the prior day's changes in positive and negative affect from morning to afternoon interacted to predict levels of OCB reported the subsequent day. As further depicted in Figure 2 and supported by simple slopes analysis (assessed at $1 \mathrm{SD}$ above and below the mean of $\mathrm{t} 2$ residual negative affect values) the relation between residual change in positive affect and subsequent-day OCB was more positive when there was a downshift in negative affect relative to an upshift in negative affect (simple slope 
$=.10$ vs. $-.03, p<.05$ vs. $n . s$.). That is, compared to those experiencing a downshift in positive affect, employees experiencing an upshift in positive affect were more likely to perform OCBs only if they simultaneously experienced a downshift rather than an upshift in negative affect. This result supported Hypothesis 1. Interestingly, however, it is worth noting that the pattern of interaction between shifts in positive and negative affect in predicting OCB shown in Figure 2 was not perfectly aligned with our theoretical prediction, because employees seemed to report a similar level of OCB for days after they experienced a downshift in positive affect coupled with an upshift in negative affect and for days after experiencing an upshift in positive affect coupled with a downshift in negative affect (hypothesized).

Hypothesis 2 focused on how shifts in positive and negative affect from morning to afternoon jointly predict the subsequent day's task performance. As shown in Table 2 (Model 1), change in positive affect during the previous day was positively related to task performance reported the following day $(B=.12, p<.01)$, while change in negative affect was not significantly related to task performance reported the following day $(B=.08, n . s$.$) . Furthermore,$ Model 2 shows that the interaction term of the residual scores of positive and negative affect significantly predicted the subsequent day's task performance $\left(B=.15, p<.01, \Delta R^{2}=.02\right)$. As further depicted in Figure 3 and supported by simple slopes analysis (assessed at 1 SD above and below the mean of $\mathrm{t} 2$ residual negative affect values), the relation between residual change in positive affect and subsequent-day task performance was more positive when there was an upshift in negative affect relative to a downshift in negative affect (simple slope $=.37$ vs. $-.03, p$ $<.01$ vs. n.s.). That is, compared to those experiencing a downshift in positive affect, employees experiencing an upshift in positive affect were able to perform their focal tasks better only if they 
simultaneously experienced an upshift rather than a downshift in negative affect. This result supported Hypothesis 2.

\section{Discussion}

The present study found that changes (shifts) in positive and negative affect over the course of a work day interacted to predict employees' OCB and task performance the following work day, such that a unique pattern of affective shift best predicted each of the two performance domains. Specifically, an upshift in positive affect gave rise to OCB more so when the upshift in positive affect was coupled with a downshift rather than an upshift in negative affect. By contrast, an upshift in positive affect contributed to task performance more so when the upshift was coupled with an upshift rather than a downshift in negative affect. In the following sections, we discuss the implications of these findings for research and practice.

\section{Theoretical Implications}

Findings from the present study contribute to the literature on affective regulation. Specifically, the results of our study extend our understanding of the affective shift processes underpinning PSI theory (Kuhl, 2000), as well as their consequences, in at least two ways. First, we delineated different forms of affective shift and their distinct consequences for employee performance. That is, we extended prior research on affective shift processes by empirically testing both a previously studied form of shift (an upshift in positive affect coupled with a downshift in negative affect [Bledow et al., 2013]; see Figure 1 quadrant A) and a more novel pattern of affective shift (upshifts in positive and negative affect; see Figure 1 quadrant B). A fruitful area of future research could involve empirically testing all possible patterns of affective shift to assess their validity in predicting unique motivational and behavioral outcomes, as guided by our theorization (see Figure 1). For instance, PSI theory posits that when 
simultaneously experiencing a downshift in positive affect and an upshift in negative affect (see Figure 1 quadrant C), employees tend to be alert to threats to their work goals (e.g., deadlines), yet remain thorough in analyzing situations and weighing advantages and disadvantages of various action plans, getting into motivational states of hesitation and preoccupation with details. It seems plausible, then, that employees experiencing this particular form of affective shift might experience a type of "analysis paralysis," whereby over-analysis of a situation prevents one from taking an appropriate course of action. Specifically, concurrent ruminative thoughts and slower, more analytical processing should prohibit these employees from selecting a particular goal implementation strategy. PSI theory also suggests that co-occurring downshifts in both positive and negative affect (see Figure 1 quadrant D) are accompanied by slow, analytical thought processes during which the broad context (e.g., current organizational culture and job market conditions) is considered in conjunction with multiple goals or ideas. Such states of decreased activation and low urgency may represent opportunities to reflect on one's overarching long-term goals and their compatibility with one another, informing larger decisions such as whether to search for a new job. In sum, a theoretical model focused on dynamic affective change may help us to better understand why employees sometimes fail to take action even when such action is desired, as well as the conditions under which employees engage in reflective processes that can help inform important career decisions.

Second, we included new domains of employee performance (i.e., OCB and task performance) as important behavioral consequences that affective shift processes may have in the workplace. Prior research on affective shift has been limited to examining employee engagement and creativity as outcomes (Bledow et al., 2011, 2013). The current study increases our understanding of the linkage between affective shift and employee behavior. 
Beyond the aforementioned contributions, evidence from the present study adds to a growing body of literature that supports the critical role of negative affect in driving positive employee outcomes (e.g., Bledow et al., 2011; Gruber et al., 2011; Thoresen et al., 2003). In particular, the daily affective dynamics examined in our study provided a more nuanced understanding of the intricate, complementary roles that shifts in positive and negative affect may play in influencing employee OCB and task performance — an understanding that has implications for both the OCB and task performance literatures. With respect to OCB, findings that increased positive affect in daily work settings leads to increased OCB only under certain conditions such as reduced negative affect, suggest that the widely accepted notion that positive affect positively predicts OCB (Lyubomirsky et al., 2005) may need to be modified. That is, fluctuations of employees' positive and negative affect might improve prediction of OCB if simultaneously taken into account.

Moreover, building upon our findings as well as those from Bledow and colleagues (2011) on the link between affective shift and work engagement, a fruitful area of future research could involve examining the potential mediational effect of work engagement on the relation between affective shift and OCB. Prior research has already linked work engagement and OCB, showing that engaged employees tend to define their work roles more broadly and invest themselves into these expanded roles (Christian, Garza, \& Slaughter, 2011). By empirically examining potential motivational mechanisms that underlie the relation between affective shift and OCB, such as work engagement, future research may shed light on the linkages between affective processes, motivational processes, and employee behavioral regulation. Additionally, in light of the interesting, unhypothesized alternative pattern of affective shift that was found to predict OCB described earlier, it would be informative for future research to examine possible alternative 
explanations for the relatively high OCB levels during days after employees experience a downshift in positive affect and an upshift in negative affect. By inducing different patterns of affective shift in laboratory or more controlled field settings, future research could further our understanding of how distinct patterns of affective shift may predict the same behavioral outcome, but perhaps, for different reasons.

With respect to task performance, past research on its relation with affect has been limited because trait and state positive and negative affect have often been studied as separate antecedents to task performance (e.g., Johnson et al., 2010; Yeo et al., 2014; Shockley et al., 2012). Our study addressed this limitation by simultaneously taking into account the dynamic shifts of both positive and negative affect, and their interaction. In particular, our finding revealed that upshifts in both positive and negative affect over the course of a work day accounted for improved task performance the following work day, which also furthers our understanding of PSI theory (Kuhl, 2000) in a context linking affective regulation with goalrelated behavioral regulation.

Finally, the results of our study offer opportunities to integrate cognition-focused motivational mechanisms into existing affect theories such that future effort could examine the sub-conscious and conscious processes that trigger affective shift and further account for subsequent motivational and behavioral consequences. For example, consistent with PSI theory, up-regulating one's intrinsic motivation has been theoretically and empirically linked to the down-regulation of negative affect and up-regulation of positive affect (Deci \& Ryan, 1991; Kuhl \& Fuhrmann, 2000). Similarly, control theory posits that change in one's perceived rate of progress toward a work goal accounts for change or shift in affect such that faster than expected progress results in increased positive affect and task motivation (Carver \& Scheier, 1990; Chang, 
Johnson, \& Lord, 2010). Following PSI theory (Kuhl, 2000), we contend that attention-focusing mechanisms (e.g., state mindfulness) may serve as mediators between affective shift and task performance. Taken together, this information suggests that one possible direction of theoretical development in affect and motivation research is to integrate PSI theory (Kuhl, 2000), control theory (Carver \& Scheier, 1990), and affective events theory (Weiss \& Cropanzano, 1996), so as to obtain a more comprehensive picture of how cognitive, motivational, and affective dynamics manifest themselves in the workplace. Such integration can be informed by intra-individual, process-focused studies that examine the underlying cognitive and motivational mechanisms between work events and affective shift, and the mechanisms between affective shift and work behavior.

\section{Limitations and Future Research}

Perhaps some of the most important limitations of the current research involve the nature in which the variables and relationships in this study were assessed. First, the measure of task performance consisted of a single item, and all measures were self-reported. As others using similar measures have noted, (e.g., Trougakos, Beal, Cheng, Hideg, \& Zweig, 2015), shortened measures of task performance do not tap more precise in-role performance behaviors. Nevertheless it is not uncommon for researchers to use single item measures in diary studies (e.g., Bakker \& Xanthopoulou, 2009). Indeed, some have argued that abbreviated and even single-item measures are valid (Wanous, Reichers, \& Hudy, 1997), and sometimes preferable in diary studies, so as not to challenge the willingness of participants to respond repeatedly and carefully (Ohly, Sonnentag, Niessen, \& Zapf, 2010). Individuals may also be best positioned to rate within-person fluctuations in their own short-term performance, since some performance changes like mastering an important skill are not observable by others (e.g., Zelenski, Murphy, \& 
Jenkins, 2008). Because the current study focuses on how short-term performance fluctuates as a result of shifts in affect, and because such short term fluctuations are unlikely to be observable by others, self-rated assessments of performance seemed appropriate.

That all of the variables are self-reported also raises the issue that common method variance (CMV) partially explains some of the relationships found in this study (Podsakoff, MacKenzie, \& Podsakoff, 2012). However, several factors should mitigate this concern. First, our study focuses on moderated relationships which are shown to be less prone to CMV-related biases (Siemsen, Roth, \& Oliveira, 2010). Second, our lagged design separating measures of affective shift and performance in time should help temper potential bias resulting from moodconsistency effects where participants' moods may contaminate their reports of performance behaviors. Lastly, we used person-mean centering for within-person analyses, which should reduce the influence of stable environmental and personal factors, such as social desirability, on the relations between daily affective changes and outcomes (Algina \& Swaminathan, 2011). In sum, although self-reported data derived from shortened measures seemed most appropriate for the current study, future studies using multiple performance indicators assessed by multiple raters could provide a more complete picture of how affective shift influences performance.

Another limitation of our research is that we measured change in affect over the course of a work day, which may not precisely correspond with how such psychological processes naturally unfold over time. Affect may, for example, fluctuate multiple times within one day under certain circumstances (Clark, Watson, \& Leeka, 1989). Likewise, certain stressors or events may be physically or psychologically present for extended periods of time, influencing affective states beyond the span of a work day. Although we had theoretical reasons to believe that a one-day time lag between affective shift and performance outcomes was appropriate, other 
time lags are also likely to be relevant. Thus, we encourage future research to explore how shifts in affect over different spans of time influence a variety of outcomes, so as to provide a more elaborate and comprehensive understanding of the affective shift process as it occurs across time and across situations.

Another limitation stems from the fact that we did not directly measure the cognitive and motivational processes that correspond with, and perhaps even drive, the effects of shifts in affect on OCB and task performance. PSI theory suggests that cognitive and motivational processes influence and are influenced by individuals' affective states. Of course, in measuring affect, we attempted to capture and infer motives and related cognitive processes by assessing how participants felt (via affect states) and behaved (via OCB and task performance). Nonetheless, research that directly examines how individuals construe their experiences before, during, and after periods of affective shift may provide a more granular understanding of how affect and cognition work in tandem to influence employees' performance.

A related point is that we did not identify and assess potential antecedents to shifts in affect, and thus we have a limited understanding of how to ignite affective states consisting of specific combinations of changes in positive and negative affect among employees. One potentially promising set of antecedents might stem from the challenge - hindrance stressor framework (Cavanaugh, Boswell, Roehling, \& Boudreau, 2000), which distinguishes between two types of stressors (challenge and hindrance). Both challenge and hindrance stressors deplete resources and result in strain. However, hindrance stressors (e.g., red tape) can impede goal progress and result in negative outcomes, whereas challenge stressors (e.g., time pressure), tend to result in positive outcomes such as job performance and increased well-being that offset the deleterious effects of strain (e.g., LePine, Podsakoff, \& LePine, 2005). 
One explanation for the positive relationship between challenge stressors and task performance might lie in the idea that challenge stressors result in simultaneous increases in positive and negative affect, and thus, signal both discrepancies in goal progress and, at the same time, an underlying commitment to meeting one's goal. Consistent with this view, experience sampling research has linked increases in challenge stressors to increases in both positive (i.e., attentiveness), and negative (i.e., anxiety) discrete emotions (Rodell \& Judge, 2009). However, the aforementioned research did not examine how challenge stressors influence the interaction between increases and decreases in positive and negative emotions and subsequent outcomes. Thus, it may be fruitful for future research to study the link between challenge stressors and affective shift, and how these shifts influence subsequent levels of task performance.

With respect to OCB, perhaps certain positive events that are not particularly stressful fuel short-term upshifts in positive affect and downshifts in negative affect, which we have shown result in higher levels of the behavior. Such events might conceivably include meeting an important deadline, receiving praise for an accomplishment at work, or attending a cheerful or celebratory workplace function (e.g., Basch \& Fisher, 2000). As previously discussed, events that enhance employees' intrinsic motivation could also contribute to upshifts in positive affect and downshifts in negative affect (Deci \& Ryan, 1991; Kuhl, 2000), further benefiting OCBs in work groups. Clearly, understanding the key antecedents of particular combinations of shift in positive and negative affect is a complex issue. More research is needed to identify these antecedents and the mechanisms through which they operate to influence specific patterns of affective shift and their outcomes.

A final limitation may also stem from the generalizability of our results. It is possible, for example, that the influence of affective shift on task performance and OCB would differ 
depending on the demands of a particular job. In an attempt to explore this issue, we reran the analyses controlling for job type, dividing jobs into technology (e.g., web administrator) and non-technology focused (e.g., salesperson) categories. We also examined whether job type might moderate the relationships between affective shift and the dependent variables using a split sample approach (two job types as subgroups), an appropriate methodology given the small person-level sample size limiting tests of a three-way interaction (Snijders, 2005; Yang et al., 2012). Controlling for job type did not meaningfully alter the pattern or statistical significance of results. Moreover, job type did not appear to moderate the relationships between affective shift and the dependent variables since the pattern of results was similar for subgroups and for the entire sample; one exception is that the interaction term for change in positive and negative affect became marginally significant in predicting OCB for the subgroups. This may have been due, however, to lower statistical power resulting from the small subgroup sample size. Thus, job type did not seem to play an important role in influencing the results of our study. Nonetheless, because our study took place within a single organizational context, future research should examine whether relationships hold for a range of jobs and tasks. For example, jobs for which inrole performance requires a high degree of creativity (e.g., marketing) might benefit more from a certain pattern of affect shift (e.g., Figure 1 quadrant A). The attention-focusing mechanism for upshifts in negative affect may also be more important for jobs with a higher cognitive load where vigilance is essential (e.g., air traffic controllers).

Future research should also examine whether the results from this study, which were collected from an organization in China, extend to western samples. Although the measures of affect used in this study have been validated across cultures (Thompson, 2007), some research has suggested that Chinese people are more likely to use suppression as an emotional 
management tactic (Butler, Lee, \& Gross, 2007; Matsumoto, Yoo, Nakagawa, 2008). Thus, if suppression of certain emotions, such as negative affect, occurred more in our sample than in an average western sample, then the variability of affect would be smaller. This restriction in range may have attenuated affect - behavior effect sizes in our sample, relative to western samples. Indeed, the standard deviations of state affect among our sample are somewhat smaller (in the low .70's and low .40's for positive and negative affect, respectively) than those reported in U.S. samples (e.g., in low-to-high .80's and in the mid-to-high .60's respectively [Rothbard \& Wilk, 2011; Watson et al., 1988]). Accordingly, the effect sizes in our study might be considered conservative estimates of the effects of affective shift on performance outcomes.

\section{Practical Implications}

Findings from our study have important practical implications for managing employee contextual and task performance. Notably, we found that somewhat distinct patterns of affective shift give rise to OCB and task performance, which is consistent with the notion that employees may not be able to simultaneously perform focal and non-focal tasks well given finite amounts of personal resources (Bolino et al., 2013). Thus, for effective management, leaders and employees should be cognizant of the different practices that foster employee OCB and task performance.

In an effort to accomplish this goal, organizations could provide management training programs focused on interpersonal emotional regulation - the process of attempting to regulate or control others' emotional experiences (Gross \& Thompson, 2007; Kotsou, Nelis, Gregoire, \& Mikolajczak, 2011). Such programs can inform managers of the factors that impact employees' affective experiences and of how particular combinations of affective experiences are likely to garner specific outcomes. 
To heighten employees' OCB, our findings suggest that managers should be trained to enhance employees' positive moods and lessen their negative moods through facilitating a variety (to reduce habituation [Landy, 1978; Lyubomirsky \& Layous, 2013]) of positive moodenhancing and negative mood-reducing conditions. Prior research suggests that elicitors of positive mood can include surprise developmental opportunities, encouragement, fun teambuilding or social events, mild flattery, and even uplifting music and videos (e.g., Baron, 1984; Basch \& Fisher, 2000; Cohen \& Lemay, 2007; Ferrer, Grenen, \& Taber, in press), whereas factors that may mitigate negative mood include lessened role ambiguity and lessened interpersonal conflict (e.g., Baron, 1984; Yang \& Diefendorff, 2009).

In order to enhance employee task performance, our findings suggest that managers should be trained to couple positive mood-generating practices with various constructive negative mood-generating practices. Supporting the effectiveness of this strategy are findings revealing that CEOs of successful companies tend to directly face organizational relevant problems (potentially increasing negative affect among employees), and simultaneously maintain confidence that the organization and its employees can ultimately prevail in addressing such obstacles (potentially increasing positive affect among employees; Collins, 2001). Positive-mood generating practices may include any of the aforementioned strategies (e.g., providing encouragement). Constructive negative mood inducing events can include increasing task-related conflict among employees, challenging solutions generated by employees, and providing feedback about goal discrepancies (e.g., Baron, 1984; Ilies \& Judge, 2005).

Beyond using management training programs, organizations can also provide employees with emotional competency training focused on enhancing individuals' capacity to identify and understand the causes and consequences of their own emotions to improve thinking and action. 
Evidence from intervention studies focused on such training (Kotsou et al., 2011) has supported the trainability of employees' emotional regulation competencies. Training of this nature can help employees themselves become better equipped to strategically regulate their feelings to influence their levels of OCB and task performance. To enhance OCB, employees can be trained to down-regulate negative mood and up-regulate positive mood via relaxation strategies and positive social event participation, respectively (e.g., Cohen \& Lemay, 2007; van der Klink, Blonk, Schene, \& van Dijk, 2001). Beyond OCB, these training programs can also help employees recognize that efforts to increase negative affect can be as important as efforts to increase positive mood for enhancing task performance. Individual strategies for increasing negative affect (e.g., anxiety) include reminding oneself of upcoming deadlines and seeking feedback from supervisors regarding discrepancies from intended goals (e.g., Carver \& Scheier, 1990).

Of course, a necessary condition for the effectiveness of the abovementioned negativemood inducing strategies is that employees are able to successfully cope with negative affect. Accordingly, emotional competency training programs should also help employees become more comfortable with embracing increased negative mood by informing them of the potential benefits of feeling negative at times (e.g., facing unpleasant work-related problems). Such awareness and enhanced emotional competencies will help employees better manage their affective fluctuations, enabling them to reap the benefits of both positive and negative affective experiences. In sum, emerging evidence has supported that both management- and employee-focused training programs can benefit effective emotional management at the individual and group levels in efforts to elicit desired work behavior. Our findings add to the growing body of evidence that can inform the content of such programs. 


\section{Conclusion}

In conducting this study, we sought to move beyond research on the independent effects of positive and negative affect levels on OCB and task performance by examining whether simultaneous shifts in positive and negative affect could better account for the influence of affect on these outcomes. Our findings revealed that the salutary effects of upshifts in positive affect on task performance were indeed enhanced when coupled with upshifts in negative affect, whereas the salutary effects of positive affect on OCB were enhanced when coupled with downshifts in negative affect. These findings add to a small but growing body of literature (Bledow et al., 2011, 2013; Kuhl, 2000) suggesting that considerable theoretical and practical value may lie in understanding not only the independent but the interactive effects of positive and negative affect on workplace outcomes. Thus, we encourage organizational scholars to continue to examine how more complex, interactive patterns of positive and negative affect influence employees and organizations. 


\section{References}

Algina, J., \& Swaminathan, H. (2011). Centering in two-level nested designs, in Joop Hox \& J. Kyle Roberts, Handbook of Advanced Multilevel Analysis. New York: Routledge

Baas, M., De Dreu, C. K. W., \& Nijstad, B. A. (2008). A meta-analysis of 25 years of moodcreativity research: Hedonic tone, activation, or regulatory focus? Psychological Bulletin, $134,779-806$.

Bakker, A. B., \& Xanthopoulou, D. (2009). The crossover of daily work engagement: Test of an actor-partner interdependence model. Journal of Applied Psychology, 94, 1562-1571.

Bandura, A. (1991). Social cognitive theory of self-regulation. Organizational Behavior and Human Decision Processes, 50, 248-287.

Baron, R. (1984). Reducing organizational conflict: An incompatible response approach. Journal of Applied Psychology, 69, 272-279.

Barsade, S., Brief, A., \& Spataro, S. (2003). The affective revolution in organizational behavior: The emergence of a paradigm. In J. Greenberg (Ed.), Organizational behavior: The state of the science (pp. 3-52). London: Lawrence Erlbaum Associates, Publishers.

Barsade, S. G., \& Gibson, D. E. (2007). Why does affect matter in organizations? Academy of Management Perspectives, 21, 36-59.

Barsade, S. G., \& Gibson, D. E. (2012). Group affect: Its influence on individual and group processes. Current Directions in Psychological Science, 21, 119-123.

Basch, J., \& Fisher, C. D. (2000). Affective events-emotions matrix: A classification of work events and associated emotions. In N. M. Ashkanasy, C. E. J. Ha“rtel, \& W. J. Zerbe (Eds.), Emotions in the workplace: Research, theory and practice (pp. 36-48). Westport CT: Quorum Books, Greenwood Publishing Group. 
Baumann, N., \& Kuhl, J. (2002). Intuition, affect, and personality: Unconscious coherence judgments and self-regulation of negative affect. Journal of Personality and Social Psychology, 83, 1213-1223.

Bledow, R., Schmitt, A., Frese, M., \& Kühnel, J. (2011). The affective shift model of work engagement. Journal of Applied Psychology, 96, 1246-1257.

Bledow, R., Rosing, K., \& Frese, M. (2013). A dynamic perspective on affect and creativity. Academy of Management Journal, 56, 432-450.

Bolino, M. C., Klotz, A. C., Turnley, W. H., \& Harvey, J. (2013). Exploring the dark side of organizational citizenship behavior. Journal of Organizational Behavior, 34, 542-559.

Bolte, A., Goschke, T., \& Kuhl, J. (2003). Emotion and intuition: Effects of positive and negative mood on implicit judgments of semantic coherence. Psychological Science, 14, 416-421.

Brewer, M. B. (2000). Research design and issues of validity. In H. T. Reis \& C. M. Judd (Eds.), Handbook of research methods in social and personality psychology (pp. 3-16). New York, NY: Cambridge University Press.

Brief, A. P., \& Weiss, H. M. (2002). Organizational behavior: Affect in the workplace. Annual Review of Psychology, 53, 279-307.

Brislin, R. W. (1980). Translation and content analysis of oral and written material. In H. C. Triandis \& J. W. Berry (Eds.), Handbook of cross-cultural psychology (Vol. 2) (pp. 349444). Boston: Allyn and Bacon.

Butler, E. A., Lee, T. L., \& Gross, J. J. (2007). Emotion regulation and culture: Are the social consequences of emotion suppression culture-specific? Emotion, 7, 30-48.

Campbell, D. T., \& Kenny, D. A. (1999). A primer on regression artifacts. New York: Guilford. 
Carver, C. S., \& Scheier, M. F. (1990). Origins and functions of positive and negative affect: A control-process view. Psychological Review, 97, 19-35.

Carver, C. S., \& White, T. L. (1994). Behavioral inhibition, behavioral activation, and affective responses to impending reward and punishment: The bis/bas scales. Journal of Personality and Social Psychology, 67, 319-333.

Cavanaugh, M. A., Boswell, W. R., Roehling, M. V., \& Boudreau, J. W. (2000). An empirical examination of self-reported work stress among U.S. managers. Journal of Applied Psychology, 85, 65-74.

Chang, C. H., Johnson, R. E., \& Lord, R. G. (2010). Moving beyond discrepancies: The importance of velocity as a predictor of satisfaction and motivation. Human Performance, $23,58-80$.

Christian, M. S., Garza, A. S., \& Slaughter, J. E. (2011). Work engagement: A quantitative review and test of its relations with task and contextual performance. Personnel Psychology, 64, 89-136.

Clark, M. S., \& Waddell, B. A. (1983). Effects of moods on thoughts about helping, attraction and information acquisition. Social Psychology Quarterly, 46, 31-35.

Clark, L. A., Watson, D., \& Leeka, J. (1989). Diurnal variation in the positive affects. Motivation and Emotion, 13, 205-234.

Cohen, S., \& Lemay, E. P. (2007). Why would social networks be linked to affect and health practices? Health Psychology, 26, 410-417.

Collins, J. (2001). Good to great: Why some companies make the leap--and others don't. New York: Harper Colllins. 
Colquitt, J. A., Scott, B. A., Rodell, J. B., Long, D. M., Zapata, C. P., Conlon, D. E., \& Wesson, M. J. (2013). Justice at the millenium, a decade later: A meta-analytic test of social exchange and affect-based perspectives. Journal of Applied Psychology, 98, 199-236.

Dalal, R., Lam, H., Weiss, H. M., Welch, E. R., \& Hulin, C. L. (2009). A within-person approach to work behavior and performance: Concurrent and lagged citizenship$\underline{\text { counterproductivity associations, and dynamic relationships with affect and overall job }}$ performance. Academy of Management Journal, 52, 1051-1066.

Deci, E. L., \& Ryan, R. M. (1991). A motivational approach to self: Integration in personality. In R. Dienstbier (Ed.), Nebraska symposium on motivation: Vol. 38. Perspectives on motivation (pp. 237-288). Lincoln: University of Nebraska Press.

Eddington, K. M., Majestic, C., \& Silvia, P. J. (2012). Contrasting regulatory focus and reinforcement sensitivity: A daily diary study of goal pursuit and emotion. Personality and Individual Differences, 53, 335-340.

Egloff, B., Tausch, A., Kohlmann, C. W., \& Krohne, H. W. (1995). Relationships between time of day, day of the week, and positive mood: Exploring the role of the mood measure. Motivation and Emotion, 19, 99-110.

Ellsworth, P. C., \& Scherer, K. R. (2003). Appraisal processes in emotion. In R. J. Davidson, H. Goldsmith \& K. R. Scherer (Eds.), Handbook of Affective Sciences. New York and Oxford: Oxford University Press.

Ferrer, R. A., Grenen, E. G., \& Taber, J. M. (in press). Effectiveness of internet-based affect induction procedures: A systematic review and meta-analysis. Emotion.

Fishbach, A., Eyal, T., \& Finkelstein, S. R. (2010). How positive and negative feedback motivate goal pursuit. Social and Personality Psychology Compass, 4, 517-530. 
Förster, J., \& Higgins, E. T. (2005). How global versus local perception fits regulatory focus. Psychological Science, 16, 631-636.

Fredrickson, B. L. (2005). The broaden-and-build theory of positive emotions. In F. A. Huppert, N. Baylis, \& B. Keverne (Ed.) The science of well-being (pp. 217-238). New York: Oxford University Press.

George, J. M. (1991). State or trait: Effects of positive mood on prosocial behaviors at work. Journal of applied Psychology, 76, 299-307.

Goldstein, A. N., \& Walker, M. P. (2014). The role of sleep in emotional brain function. Annual Review of Clinical Psychology, 10, 679-708.

Goodman, S. A., \& Svyantek, D. J. (1999). Person-organization fit and contextual performance: Do shared values matter. Journal of Vocational Behavior, 55, 254-275.

Gross, J. J., \& Thompson, R. A. (2007). Emotion regulation: Conceptual foundations. In J. G. Gross (Ed.), Handbook of emotion regulation (pp. 3-24). New York: Guilford Press.

Gruber, J., Mauss, I. B., \& Tamir, M. (2011). A dark side of happiness? How, when, and why happiness is not always good. Perspectives on Psychological Science, 6, 222-233.

Higgins, E. T. (1997). Beyond pleasure and pain. American Psychologist, 52, 1280-1300.

Ilies, R., \& Judge, T. A. (2005). Goal regulation across time: The effect of feedback and affect. Journal of Applied Psychology, 90, 453-467.

Izard, C. E. (2009). Emotion theory and research: Highlights, unanswered questions, and emerging issues. Annual Review of Psychology, 60, 1-26.

Johnson, R. E., Tolentino, A. L., Rodopman, O. B., \& Cho, E. (2010). We (sometimes) know not how we feel: Predicting job performance with an implicit measure of trait affectivity. Personnel Psychology, 63, 197-219. 
Judge, T. A., Simon, L. S., Hurst, C., \& Kelley, K. (2014). What I experienced yesterday is who I am today: Relationship of work motivations and behaviors to within-individual variation in the five-factor model of personality. Journal of Applied Psychology, 99, 199221

Kazén, M., \& Kuhl, J. (2005). Intention memory and achievement motivation: Volitional facilitation and inhibition as a function of affective contents of need-related stimuli. Journal of Personality and Social Psychology, 89, 426-448.

Kotsou, I., Nelis, D., Gregoire, J., \& Mikolajczak, M. (2011). Emotional plasticity: Conditions and effects of improving emotional competence in adulthood. Journal of Applied Psychology, 96, 827-839.

Kuhl, J. (2000). A functional-design approach to motivation and self-regulation: The dynamics of personality systems interactions. In M. Boekaerts, P. R. Pintrich \& M. Zeidner (Eds.), Handbook of self-regulation (pp.111-169). San Diego: Academic.

Kuhl, J., \& Fuhrmann, A. (2000). Volitional Components Questionnaire 3 (VCQ-3). University of Osnabrück, Germany.

Kuhl, J., \& Kazén, M. (1999). Volitional facilitation of difficult intentions: Joint activation of intention memory and positive affect removes stroop interference. Journal of Experimental Psychology, 128, 382-399.

Kuhl, J., \& Koole, S. L. (2008). The functional architecture of approach and avoidance motivation. In A. J. Elliot (Ed.), Handbook of approach and avoidance motivation (pp. 535-555). New York: Taylor \& Francis.

Landy, F. J. (1978). An opponent process theory of job satisfaction. Journal of Applied Psychology, 63, 533-547. 
Lazarus, R. S. (1991). Cognition and motivation in emotion. American Psychologist, 46, 352-367.

Lanaj, K., Chang, C. H., \& Johnson, R. E. (2012). Regulatory focus and work-related outcomes: a review and meta-analysis. Psychological bulletin, 138, 998-1034.

LePine, J. A., Podsakoff, N. P., LePine, M. A. (2005). A meta-analytic test of the challenge $\underline{\text { stressor-hindrance stressor framework: An explanation for inconsistent relationships }}$ among stressors and performance. Academy of Management Journal, 48, 764-775.

Locke, E. A., \& Latham, G. P. (2006). New directions in goal-setting theory. Current Directions in Psychological Science, 15, 265-268.

Lyubomirsky, S., King, L., \& Diener, E. (2005). The benefits of frequent positive affect: does happiness lead to success? Psychological Bulletin, 131, 803-855.

Lyubomirsky, S. \& Layous, K. (2013). How do simple positive activities increase well-being? Current Directions in Psychological Science, 22, 57 - 62.

Matsumoto, D., Yoo, S. H., \& Nakagawa, S. (2008). Culture, emotion regulation, and adjustment. Journal of Personality and Social Psychology, 94, 925-937.

McRae, K. Ochsner, K. N., Mauss, I. B., Gabrieli, J. J. D., \& Gross, J. J. (2008). Gender differences in emotion regulation: An fMRI study of cognitive reappraisal. Group Processes \& Intergroup Relations, 11, 143-162.

Motowidlo, S. F., \& Kell, H. J. (2013). Job performance. In Neal W. Schmitt, Scott Highhouse, \& Irving B. Weiner (Eds), Industrial and Organizational Psychology of Handbook of Psychology (2nd Ed., Vol. 12, pp. 82-103). Hoboken, New Jersey: John Wiley \& Sons, Inc.

Muthén, L. K., \& Muthén, B. O. (1998-2013). Mplus User's Guide (7th ed.). Los Angeles, CA: Muthén \& Muthén. 
Ng, T. W. H., \& Feldman, D. C. (2010). Organizational tenure and job performance. Journal of Management, 36, 1220-1250.

Ohly, S., Sonnentag, S., Niessen, C., \& Zapf, D. (2010). Diary studies in organizational research. Journal of Personnel Psychology, 9, 79-93.

Organ, D. W. (1997). Organizational citizenships behavior: It's construct cleanup time. Human Performance, 10, 85-97.

Podsakoff, P. M., MacKenzie, S. B., \& Podsakoff, N. P. (2012). Sources of method bias in social $\underline{\text { science research and recommendations on how to control it. Annual Review of }}$ Psychology, 63, 539-569.

Rothbard, N. P., \& Wilk, S. L. (2011). Waking up on the right or wrong side of the bed: Start-ofworkday mood, work events, employee affect, and performance. Academy of Management Journal, 54, 959-980.

Rodell, J. B., \& Judge, T. A. (2009). Can "good" stressors spark "bad" behavior? The mediating role of emotions in links of challenge and hindrance stressors with citizenship and counterproductive behaviors. Journal of Applied Psychology, 94, 1438-1451

Rogosa, D., Brandt, D., \& Zimowski, M. (1982). A growth curve approach to the measurement of change. Psychological Bulletin, 92, 726-748.

Shackman, A. J., Salomons, T. V., Slagter, H. A., Fox, A. S., Winter, J. J., \& Davidson, R. K. (2011). The integration of negative affect, pain, and cognitive control in the cingulate cortex. Nature Reviews Neuroscience, 12, 154-167.

Shockley, K. M., Ispas, D., Rossi, M. E., \& Levine, E. L. (2012). A meta-analytic investigation of the relationship between state affect, discrete emotions, and job performance. Human Performance, 25, 377-411. 
Siemsen, E., Roth, A., \& Oliveira, P. (2010). Common method bias in regression models with linear, quadratic, and interaction effects. Organizational Research Methods, 13, 456-476.

Snijders, T. A. B. (2005). Power and sample size in multilevel linear models. In B. S. Everitt \& D. C. Howell (Eds.), Encycopedia of statistics in behavioral science (pp.1570-1573). Chichester, UK: Wiley.

Thompson, E. R. (2007). Development and validation of an internationally reliable short-form of the positive and negative affect schedule (PANAS). Journal of Cross-Cultural Psychology, 38, 227-242.

Thoresen, C. J., Kaplan, S., Barsky, A., Warren, C., \& de Chermont, K. (2003). The affective underpinnings of job perceptions and attitudes: A meta-analytic review and integration. Psychological Bulletin, 129, 914-945.

Trougakos, J. P., Beal, D. J., Cheng, B. H., Hideg, I., \& Zweig, D. (2015). Too drained to help: A resource depletion perspective on daily interpersonal citizenship behaviors. Journal of Applied Psychology, 100, 227-236.

van der Klink, J. J., Blonk, R. W., Schene, A. H., \& van Dijk, F. J. (2001). The benefits of interventions for work-related stress. American Journal of Public Health, 91, 270-276.

van der Helm, E., \& Walker, M. P. (2009). Overnight therapy? The role of sleep in emotional brain processing. Psychological Bulletin, 135, 731-748.

Vroom, V. H. (1964). Work and motivation. Oxford, England: Wiley.

Wanous, J. P., Reichers, A. E., \& Hudy, M. J. (1997). Overall job satisfaction: How good are single-item measures? Journal of Applied Psychology, 82, 247-252. 
Watson, D. (1988). Intraindividual and interindividual analyses of positive and negative affect: Their relation to health complaints, perceived stress, and daily activities. Journal of Personality and Social Psychology, 54, 1020-1030.

Watson, D., Clark, L. A., \& Tellegen, A. (1988). Development and validation of brief measures of positive and negative affect: the PANAS scales. Journal of Personality and Social Psychology, 54, 1063-1070.

Weiss, H. M., \& Cropanzano, R. (1996). Affective events theory: A theoretical discussion of the $\underline{\text { structure, causes and consequences of affective experiences at work. Research in }}$ Organization Behavior, 18, 1-74.

Yang, J., \& Diefendorff, J. M. (2009). The relations of daily counterproductive workplace behavior with emotions, situational antecedents, and personality moderators: A diary study in Hong Kong. Personnel Psychology, 62, 259-295.

Yang, L. Q., Spector, P. E., Sanchez, J. I., Allen, T. D., Poelmans, S., Cooper, C.L., ... \& Woo, J. M. (2012). Individualism-collectivism as a moderator of the work demands-strains relationship: A cross-level and cross-national examination. Journal of International Business Studies, 43, 424-443.

Yeo, G. B., Frederiks, E. R., Kiewitz, C., \& Neal, A. (2014). A dynamic, self-regulatory model of affect and performance: Interactions between states, traits and task demands. Motivation and Emotion, 38, 429-443.

Zelenski, J. M., Murphy, S. A., \& Jenkins, D. A. (2008). The happy-productive worker thesis revisited. Journal of Happiness Studies, 9, 521-537. 


\section{Footnotes}

1 Although this research is primarily focused on the influence of affective shift on OCB and task performance, it is, of course, also important to acknowledge the role of cognition. Research suggests that affect and cognition are largely intertwined, with affect influencing cognition and vice versa. As noted by Ellsworth and Scherer (2003), “Thinking and feeling are inextricably interrelated most of the time: Certain ways of interpreting one's environment are inherently emotional, few thoughts are entirely free of feelings, and emotions influence thinking” (p. 572). Such a view is consistent with PSI theory (Kuhl, 2000), as well as with recent theorizing in the organizational sciences on the influence of both affect and cognition on OCB and task performance (e.g., Colquitt et al., 2013). Thus, although we rely exclusively on measures of affect to predict OCB and task performance, we assume that cognition plays a significant role in formulating and regulating these affective processes and that shifts in affect also influence cognition.

2 The present study is the first publication from a larger data collection effort as described in the Method section.

3 One may be curious about whether using scores of the shorter-version PANAS (10 items in total) from both the morning and afternoon surveys would lead to study results that are the same as those reported in the current manuscript. We did re-run all of the analyses to examine this possibility, and found the pattern of results to be nearly identical to those reported in the present paper. The one small difference was that the simple slope for the relationship between change in positive affect and OCB among employees with decreased negative affect became marginally significant (i.e., $p=.07$ vs. $p<.05$ in the present paper) - albeit the regression coefficient was almost the same (.11 vs. .10 in the current paper). 
Table 1

Means, Standard Deviations, and Correlations between Focal Variables

\begin{tabular}{|c|c|c|c|c|c|c|c|c|c|c|c|c|c|c|c|c|}
\hline Variable & Mean & S.D. & 1 & 2 & 3 & 4 & 5 & $\overline{6}$ & 7 & 8 & 9 & 10 & 11 & 12 & 13 & 14 \\
\hline \multicolumn{17}{|l|}{ Day-Level Variables } \\
\hline $\begin{array}{l}\text { 1. Organizational citizenship } \\
\text { behavior (lagged) }\end{array}$ & 0.54 & 0.35 & - & -.02 & .06 & .01 & $.07 *$ & -.02 & .00 & .06 & -.05 & -.03 & & & & \\
\hline 2. Task performance (lagged) & 2.76 & 0.74 & $.30 * *$ & - & $.19 * *$ & $.12 * *$ & $.15^{* *}$ & $.13^{* *}$ & .03 & .03 & $-.07 *$ & -.01 & & & & \\
\hline 3. Positive affect (t1) & 2.27 & 0.76 & $.64 * *$ & $.59 * *$ & - & $.28^{* *}$ & $.23 * *$ & $.14 * *$ & -.01 & .05 & -.06 & .02 & & & & \\
\hline 4. Negative affect (t1) & 1.31 & 0.38 & .23 & .07 & .20 & - & $.21 * *$ & $.32 * *$ & -.05 & .06 & -.01 & -.02 & & & & \\
\hline 5. Positive affect (t2) & 2.27 & 0.67 & $.62 * *$ & $.57 * *$ & $.96^{* *}$ & .20 & - & $.21 * *$ & -.01 & -.02 & -.01 & .00 & & & & \\
\hline 6. Negative affect (t2) & 1.30 & 0.43 & $.34 * *$ & .05 & .22 & $.91 * *$ & .22 & - & .02 & .00 & -.04 & -.01 & & & & \\
\hline 7. Monday & - & - & - & - & - & - & - & - & - & $-.25 * *$ & $-.25 * *$ & $-.25^{* *}$ & & & & \\
\hline 8. Tuesday & - & - & - & - & - & - & - & - & - & - & $-.25^{* *}$ & $-.25^{* *}$ & & & & \\
\hline 9. Thursday & - & - & - & - & - & - & - & - & - & - & - & $-.25^{* *}$ & & & & \\
\hline 10. Friday & - & - & - & - & - & - & - & - & - & - & - & - & & & & \\
\hline \multicolumn{17}{|l|}{ Person-Level Variables } \\
\hline 11. Positive affectivity & 3.23 & .71 & $.39 * *$ & $.34 * *$ & $.46 * *$ & .05 & $.44 * *$ & .06 & - & - & - & - & - & & & \\
\hline 12. Negative affectivity & 1.88 & .52 & -.15 & .08 & -.09 & $.36 * *$ & -.08 & .21 & - & - & - & - & .16 & - & & \\
\hline 13. Missing days & 2.23 & 2.56 & .18 & .04 & .00 & .13 & -.04 & $.26^{*}$ & - & - & - & - &. .23 & -.04 & - & \\
\hline 14. Gender & 0.49 & 0.50 & .04 & -.10 & -.09 & .09 & -.03 & .08 & - & - & - & - & -.06 & -.08 & -.08 & - \\
\hline 15. Tenure (years) & 2.40 & 1.89 & -.06 & $-.24 *$ & -.14 & .09 & -.09 & .07 & - & - & - & - & $-.32 * *$ & .07 & -.09 & -.07 \\
\hline
\end{tabular}

Note. Correlations above the diagonal represent the day level $(\mathrm{n}=1065)$ and are pooled within-person correlations. Correlations below the diagonal represent the person level $(n=71)$. Variables that were measured at the day level were aggregated across days to calculate person-level correlations. Affect variables labeled "t1" and " 2 " were measured in the morning and afternoon, respectively; variables labeled "lagged" indicate afternoon measurement following the day of the affect measurements; "-"s indicate values not available. Day of the week was coded as four dummy variables with Wednesday as the reference group. $* p<.05 * * p<.01$. 
Table 2

Multilevel Estimates for Models Predicting OCB and Task Performance

\begin{tabular}{|c|c|c|c|c|}
\hline \multirow[b]{2}{*}{ Independent variable } & \multicolumn{2}{|c|}{ Model 1} & \multicolumn{2}{|c|}{ Model 2} \\
\hline & OCB & $\begin{array}{c}\text { Task } \\
\text { Performance } \\
\end{array}$ & OCB & $\begin{array}{c}\text { Task } \\
\text { Performance } \\
\end{array}$ \\
\hline Intercept & $.13(.83)$ & $2.77 * *(.95)$ & $.24(.80)$ & $2.53 * *(.92)$ \\
\hline \multicolumn{5}{|l|}{ Day-Level Variables } \\
\hline Positive affect (t1) & $.04(.04)$ & $.14 * *(.04)$ & $.03(.03)$ & $.15^{* *}(.04)$ \\
\hline Negative affect (t1) & $-.03(.05)$ & $.01(.05)$ & $-.05(.04)$ & $.04(.05)$ \\
\hline Positive affect (t2) & $.03(.04)$ & $.12 * *(.04)$ & $.06(.03)$ & $.10 * *(.03)$ \\
\hline Negative affect (t2) & $.07 * *(.02)$ & $.08(.07)$ & $.07 *(.03)$ & $.07(.06)$ \\
\hline $\begin{array}{l}\text { Positive affect (residual) } \times \\
\text { Negative affect (residual) }\end{array}$ & & & $-.15^{*}(.06)$ & $.15^{* *}(.05)$ \\
\hline Monday & $-.01(.06)$ & $.08(.10)$ & $.00(.06)$ & $.07(.10)$ \\
\hline Tuesday & $.04(.06)$ & $-.01(.09)$ & $.04(.06)$ & $-.01(.09)$ \\
\hline Thursday & $-.02(.06)$ & $-.18(.11)$ & $-.03(.06)$ & $-.17(.10)$ \\
\hline Friday & $.01(.10)$ & $.02(.11)$ & $-.00(.10)$ & $.03(.11)$ \\
\hline Residual variance at day level & $.99 * *(.01)$ & $.93 * *(.02)$ & $.97 * *(.01)$ & $.91 * *(.02)$ \\
\hline \multicolumn{5}{|l|}{ Person-Level Variables } \\
\hline Positive affectivity & $.42 * *(.11)$ & $.35 * *(.13)$ & $.40 * *(.11)$ & $.40^{* *}(.13)$ \\
\hline Negative affectivity & $-.24 *(.10)$ & $.02(.12)$ & $-.24 *(.10)$ & $.01(.11)$ \\
\hline Number of missed days & $.01(.19)$ & $-.17(.12)$ & $-.00(.19)$ & $-.14(.12)$ \\
\hline Gender & $.21(.19)$ & $-.17(.24)$ & $.22(.20)$ & $-.19(.23)$ \\
\hline Tenure (years) & $.11(.09)$ & $-.16(.11)$ & $.13(.09)$ & $-.19(.11)$ \\
\hline Residual variance at person level & $.81 * *(.12)$ & $.81 * *(.11)$ & $.83 * *(.11)$ & $.76^{* *}(.12)$ \\
\hline$R^{2}($ Day-Level $)$ & $.01(.01)$ & $.07 * *(.02)$ & $.03 * *(.01)$ & $.09 * *(.02)$ \\
\hline$\Delta R 2$ & & & .02 & .02 \\
\hline
\end{tabular}

Note. Regression coefficients and $R^{2}$ values were standardized estimates from the Mplus output corresponding to the multi-level models. Standard errors were reported in parentheses. Affect variables labeled " $t 1$ " and " $\mathrm{t} 2$ " were measured in the morning and afternoon, respectively $* p<.05 * * p<.01$. 


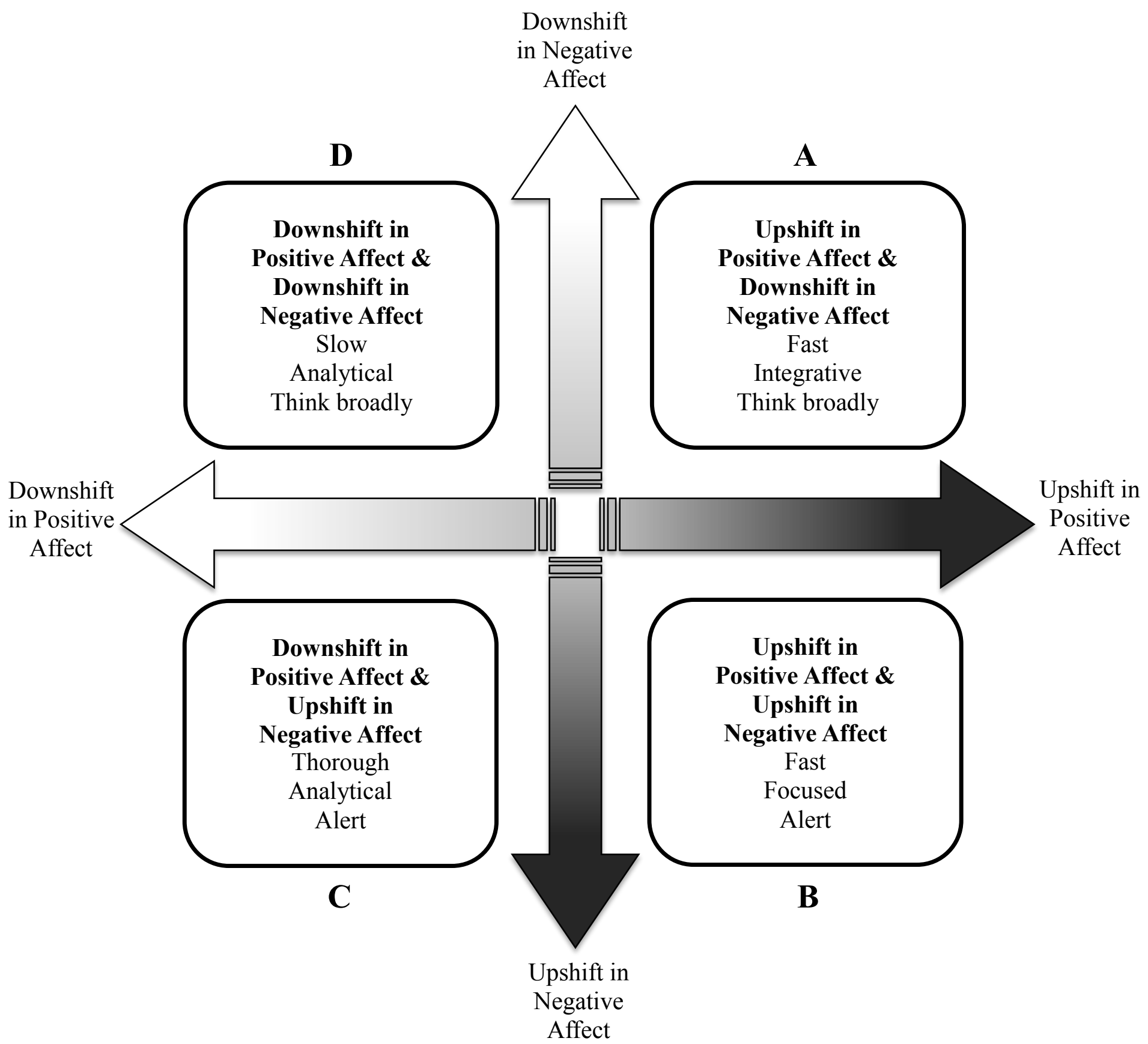

Figure 1. Motivational implications of affective shift in positive and negative affect 


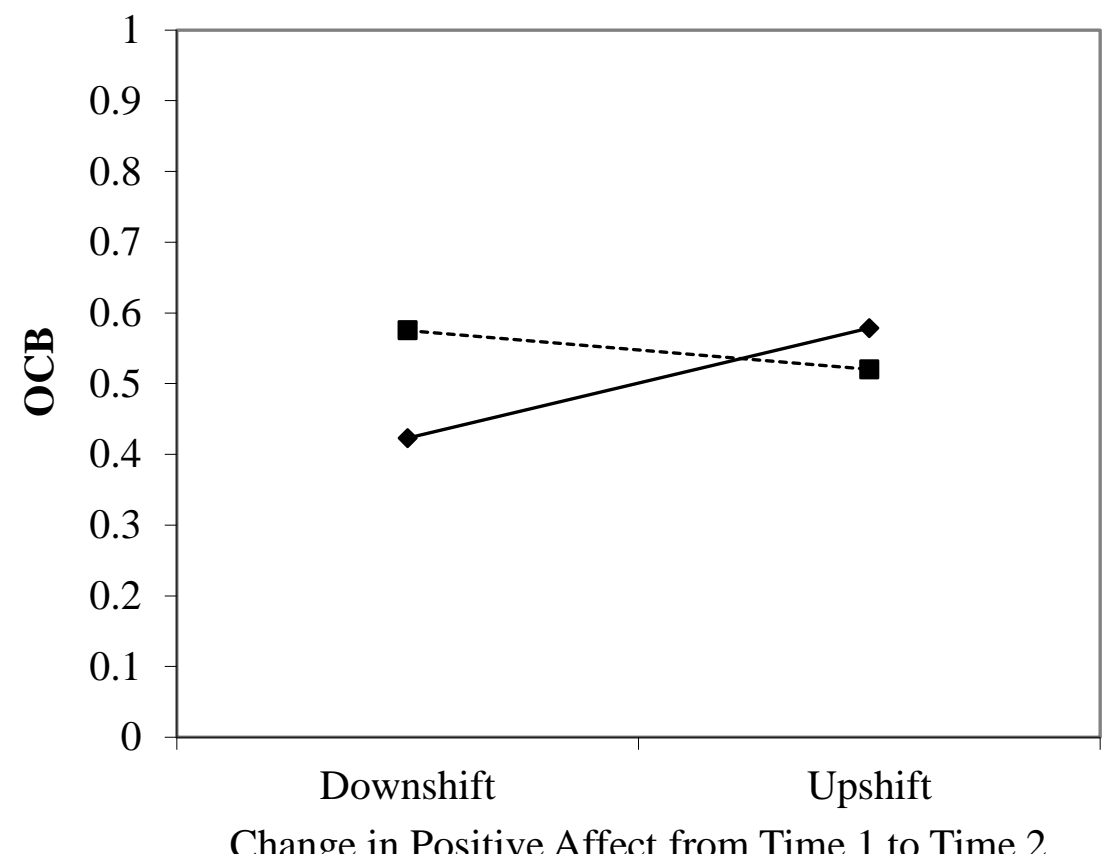

$$
\begin{aligned}
& \text { Change in } \\
& \text { Negative } \\
& \text { Affect } t_{1}-t_{2}: \\
& \longrightarrow \text { Downshift } \\
& --- \text { Upshift }
\end{aligned}
$$

Change in Positive Affect from Time 1 to Time 2

Figure 2. Affective shift and OCB 


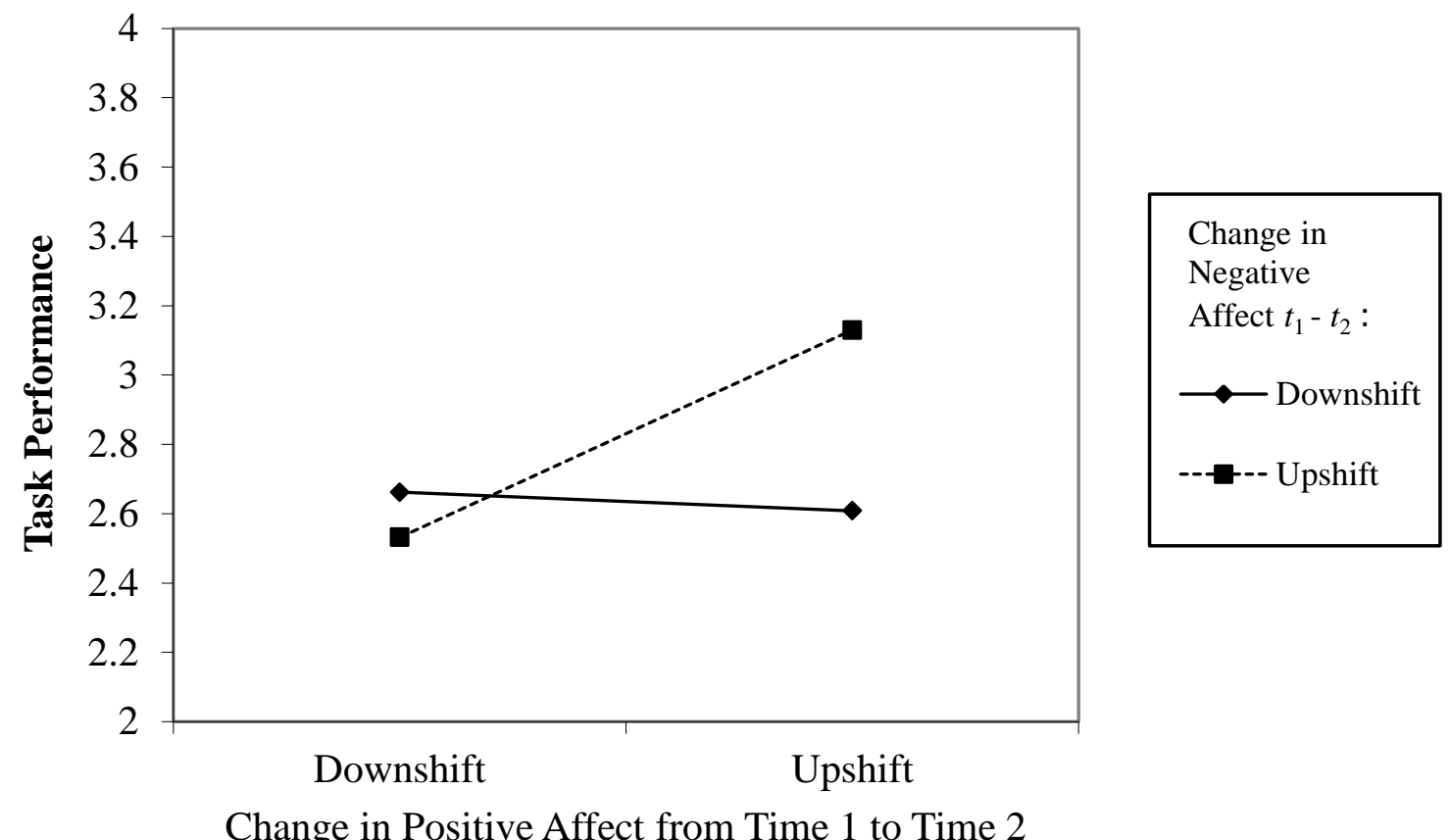

Figure 3. Affective shift and task performance 